ARTICLE

https://doi.org/10.1057/s41599-019-0298-6

\title{
Subtle differentiation of countries' responsibilities under the Paris Agreement
}

Pieter Pauw (10) 1,2,4, Kennedy Mbeva ${ }^{5,6}$ \& Harro van Asselt ${ }^{3,7}$

\begin{abstract}
To be effective and secure participation, a global climate change agreement needs to be perceived as fair by the countries involved in it. The Paris Agreement approached differentiation of countries' responsibilities to address climate change by departing from the rigid distinction between industrialised and developing countries through the inclusion of 'subtle differentiation' of specific subsets of countries (e.g., Least Developed Countries) for certain substantive issues (e.g., climate finance) and/or for specific procedures (e.g., timelines and reporting). In this article, we analyse whether the self-differentiation countries followed when formulating their own climate plans, or nationally determined contributions (NDCs), is consistent with the Paris Agreement's subtle differentiation. We find that there is consistency for mitigation and adaptation, but not for support (climate finance, technology transfer and capacity building). As NDCs are the main instrument for achieving the Paris Agreement's long-term goals, this inconsistency needs to be addressed to allow subsequent rounds of NDCs to be more ambitious.
\end{abstract}

\footnotetext{
${ }^{1}$ Frankfurt School of Finance and Management, Frankfurt am Main, Germany. ${ }^{2}$ Copernicus Institute of Sustainable Development, Utrecht University, Utrecht, the Netherlands. ${ }^{3}$ Stockholm Environment Institute, Stockholm, Sweden. ${ }^{4}$ German Development Institute, Bonn, Germany. ${ }^{5}$ University of Melbourne, Melbourne, Australia. ${ }^{6}$ African Centre for Technology Studies, Nairobi, Kenya. ${ }^{7}$ University of Eastern Finland, Joensuu, Finland. Correspondence and requests for materials should be addressed to P.P. (email: w.p.pauw@gmail.com)
} 


\section{Introduction}

1 hile countries are formally equal in the United Nations (UN) climate negotiations, their contribution to greenhouse gas (GHG) emissions, development needs, and vulnerability to climate change vary greatly. These differences have been addressed by acknowledging countries' 'common but differentiated responsibilities and respective capabilities' (CBDRRC) in the UN Framework Convention on Climate Change (UNFCCC).

A dichotomous interpretation of CBDR-RC enabled international agreement on the Convention and its Kyoto Protocol. Industrialised (Annex I) countries committed to absolute emission reduction or limitation targets, whereas all other (nonAnnex I) countries had no such obligations. This rigid distinction, however, does not reflect the dynamic diversification among developing countries since 1992, as reflected in diverging contributions to global emissions and economic growth patterns (Deleuil, 2012; Dubash, 2009). This has led Depledge and Yamin $(2009,443)$ to label the Annex I/non-Annex I dichotomy introduced by the UNFCCC 'dysfunctional' and 'the regime's greatest weakness'.

The Paris Agreement did not dissolve this dichotomy. It also did not introduce new ways of allocating emissions among countries, such as convergence towards equal per capita emissions, or differentiating based on survival versus luxury emissions (see Kartha et al. 2018; IPCC, 2013). Nevertheless, the Paris Agreement moves on from the 1992 dichotomy in at least three ways.

First, it follows a more nuanced and dynamic interpretation of CBDR-RC. The Paris Agreement distinguishes between 'developed' and 'developing' countries instead of Annex I and nonAnnex I countries. This allows developing countries to increase their ambitions over time without formally 'graduating' to Annex I (Voigt and Ferreira, 2016). This is further reflected by the Paris Agreement's addition of the phrase 'in the light of national circumstances' to the notion of CBDR-RC: as countries' circumstances evolve, so too will their common but differentiated responsibilities (Rajamani, 2016).

Second, the Paris Agreement introduces bounded selfdifferentiation of countries' responsibilities through their national climate action plans, known as nationally determined contributions (NDCs). These climate action plans are universal (i.e., each country formulates one), bottom-up (i.e., countries set their own priorities and ambitions) (Mbeva and Pauw, 2016) and 'contributions' rather than the harder 'commitments' commonly used in international treaties (Rajamani, 2015). Selfdifferentiation is bounded by the notions of 'progression' and 'highest possible ambition' that NDCs need to abide by (Voigt and Ferreira, 2016).

Third, the Paris Agreement differentiates between countries in a context-specific and often subtle manner. We define this 'subtle differentiation' as subtlety towards specific subsets of countries (e.g., Least Developed Countries (LDCs) and Small Island Developing States (SIDS)) on specific issues (e.g., adaptation finance) and/or procedures (e.g., timelines and reporting).

Inconsistency between subtle differentiation of the Paris Agreement and self-differentiation of NDCs could, at a minimum, result in countries refusing to make their NDCs more ambitious because they perceive other countries' NDCs as less ambitious (see Grieco et al., 1993; Mearsheimer, 1994). This in turn, may create negotiating difficulties in the run-up towards updating NDCs by 2020 and beyond. At worst, it could put the Paris Agreement's ambition mechanism at risk: if countries are cautious or reluctant to ratchet up their ambition over time, it is more likely that the long-term goals of the Paris Agreement will be missed.
This article offers a novel approach that complements existing research on how to ensure fairness in international climate policy through NDCs. Existing research includes the bottom-up approach followed by Winkler et al. (2018), who study countries' justifications for fairness in NDCs. They show that countries have put forward a wide variety of hardly substantiated indicators and approaches. By contrast, the top-down approach by Du Pont et al. (2017), Brown et al. (2018), Zimm and Nakicenovic (2019) and Climate Action Tracker (n.d.) compares NDC ambitions with global emission reduction goals under different equity assumptions. Such assessments make normative judgements on emission allocations that have limitations (Kartha et al., 2018), especially in the absence of an operational definition of CBDR-RC under the UNFCCC. By examining consistency with the subtle differentiation put forward in the Paris Agreement, we seek to provide a substantiated approach on how to ensure fairness through NDCs, while eschewing normative judgements on what constitutes a 'fair' contribution.

From a rigid dichotomy to subtle differentiation. Reflecting a narrow framing of climate change as an environmental (i.e., pollution control) problem rather than a developmental problem (see Hermwille et al., 2017; Makomere and Mbeva, 2018), the fairness of climate action through CBDR-RC has typically been discussed in the context of mitigation (Ciplet et al., 2013; Klinsky and Winkler, 2014). However, the notions of equity and CBDRRC in the UNFCCC are not limited to mitigation (UN, 1992, Article 3.1). Considerations of equity should therefore encompass other elements of international climate policy, such as vulnerability to climate impacts, finance, and technology transfer (BASIC Experts, 2011; Climate Action Network, 2013; Klinsky and Winkler, 2014; Pauw et al., 2014).

That said, the 1992 UNFCCC differentiates between Annex I Parties with respect to some of the core mitigation commitments, such as the commitment to adopt policies and measures in Article 4.2(a). More importantly, the commitments in the Convention were based primarily on whether countries were included in Annex I (a list of countries that then comprised the OECD plus additional states undergoing the process of transition to a market economy) or Annex II (a subset of Annex I, including the thenOECD countries). Other country categories are nonetheless mentioned. For instance, a wide range of developing country categories is listed in the context of considering the impacts of climate change and the impact of implementation of response measures, including small island countries, countries with fragile ecosystems, fossil fuel-producing countries, landlocked countries, and so on (Article 4.8). Furthermore, Parties need to take into account the specific needs and special situations of LDCs in the context of technology transfer (Article 4.9).

The 1997 Kyoto Protocol included emission reduction or limitation targets for Annex I countries, but not for non-Annex I countries. The Protocol therefore only cemented the mitigation focus and strengthened the dichotomy.

The non-legally binding 2009 Copenhagen Accord that only received support of 114 out of 194 Parties (UNFCCC, 2010) -in many ways a precursor for the Paris Agreement (Bodansky, 2016) - signaled a move away from the Annex I/non-Annex I dichotomy by suggesting that LDCs and SIDS have more flexibility than other non-Annex I countries in implementing mitigation actions (UNFCCC, 2010: para. 5). Furthermore, it prioritises adaptation finance for the 'most vulnerable developing countries', specifically mentioning LDCs, SIDS and Africa (UNFCCC, 2010: para. 8). Lastly, 'incentives' should be provided for 'low-emitting' developing countries (without defining these), 


\section{Table 1 Subtle differentiation in the Paris Agreement (authors' compilation)}

\begin{tabular}{|c|c|c|}
\hline Article & Subtle differentiation with respect to: & Subject and context of subtle differentiation \\
\hline Preamble & particularly vulnerable developing countries & Specific needs and special circumstances \\
\hline Preamble & LDCs & Specific needs and special situations with regard to funding and technology transfer \\
\hline 4.6 & LDCs, SIDS & Mitigation: provide low-GHG development plans, strategies and actions \\
\hline 4.15 & $\begin{array}{l}\text { economies most affected by impacts of response } \\
\text { measures }\end{array}$ & Mitigation: impacts of mitigation measures on economies \\
\hline 6.6 & particularly vulnerable developing countries & Mitigation mechanism: share of proceeds as financial assistance for adaptation \\
\hline 7.2 & particularly vulnerable developing countries & Adaptation as key component of and contribution to response to climate change \\
\hline 7.6 & particularly vulnerable developing countries & $\begin{array}{l}\text { Adaptation: recognise importance of support and international cooperation on } \\
\text { adaptation and needs of developing countries }\end{array}$ \\
\hline 9.2 & Other (non-developed) Parties & Finance: provision of voluntary support \\
\hline 9.4 & LDCs and SIDS & Finance: for mitigation and adaptation \\
\hline 9.5 & Other (non-developed) Parties & Finance: voluntary communication on support provided \\
\hline 9.7 & Other (non-developed) Parties & Finance: voluntary provision of provided and mobilised finance \\
\hline 9.9 & LDCs and SIDS & Finance: simplified approval procedures and enhanced readiness support \\
\hline 11.1 & Countries with least capacity, such as LDCs & Capacity building: enhance capacity and abilities of developing countries \\
\hline 11.1 & particularly vulnerable countries, such as SIDS & Capacity building: enhance capacity and abilities of developing countries \\
\hline 11.4 & $\begin{array}{l}\text { All Parties that enhance the capacities of } \\
\text { developing countries }\end{array}$ & Capacity building: communicate on actions and measures \\
\hline 13.2 & $\begin{array}{l}\text { Developing countries needing flexibility in light } \\
\text { of their capacities }\end{array}$ & Transparency framework: implement provisions \\
\hline 13.3 & LDCs and SIDS & Transparency framework: recognise special circumstances \\
\hline 13.9 & $\begin{array}{l}\text { Other (non-developed) Parties that provide } \\
\text { support }\end{array}$ & $\begin{array}{l}\text { Transparency framework: provide information on finance, technology transfer and } \\
\text { capacity building }\end{array}$ \\
\hline 13.11 & $\begin{array}{l}\text { Developing countries needing assistance in the } \\
\text { light of their capacities }\end{array}$ & $\begin{array}{l}\text { Transparency framework: provision of (1) national inventory of emissions; (2) } \\
\text { information to track progress on NDC implementation; and ( } 3 \text { ) information on provision } \\
\text { of finance, technology transfer and capacity building }\end{array}$ \\
\hline
\end{tabular}

for them to continue low-emission development (UNFCCC, 2010: para. 7).

Compared to the UNFCCC, the Kyoto Protocol, and even the Copenhagen Accord, subtle differentiation is much more prominent in the 2015 Paris Agreement (see Table 2 in the online supplementary material). There are 19 instances of subtle differentiation with respect to subsets of countries, certain substantive issues or procedures (see Table 1). It is most evident with respect to finance and capacity building, but also apparent with regard to mitigation, adaptation, technology transfer (both in the preamble and Article 13, but not in Article 10 on technology transfer) and the transparency framework. In that sense, subtle differentiation covers the main aims of the Paris Agreement as outlined in Article 2 (mitigation, adaptation and finance), even if subtle differentiation is absent in this provision itself. No differentiation is visible in Article 8 on loss and damage, because it does not include any commitments for Parties other than 'enhancing understanding' (UNFCCC, 2015, Article 8.3).

In terms of specific subsets of countries, the Paris Agreement repeats the Convention's reference to economies most affected by the impacts of mitigation measures (Article 4.15) but leaves out the Copenhagen Accord's reference to Africa. However, the Agreement contains multiple references to LDCs (six times) and SIDS (five times), mostly in relation to their limited capacity and high vulnerability. New are the references to 'other' (nondeveloped country) Parties, who are invited to provide financial support on a voluntary basis (Article 9.2) and communicate information about support provided (Article 9.5, 9.7, 13.9).

In terms of differentiation regarding procedures, LDCs and SIDS are granted flexibility in preparing mitigation actions (Article 4.6); particularly vulnerable countries shall receive a share of the proceeds from the mitigation mechanism to meet the costs of adaptation (Article 6.6); and non-developed 'other Parties' that provide financial support are encouraged to communicate this (Article 9.5 and 9.7).

In short, over time, subtle differentiation under the UNFCCC has both become more prevalent and extensive. The next section explains whether this de jure subtle differentiation in the Paris Agreement is consistent with de facto self-differentiation in the NDCs.

\section{Results}

To assess whether self-differentiation is consistent with subtle differentiation, we distinguished three country categories: developed countries listed in Annex I of the UNFCCC; LDCs and SIDS (in line with the subtle differentiation in the Paris Agreement), and the remaining countries (which we term 'emerging countries'). We analysed whether these country categories show discernible cascading results with respect to the identified subtle differentiation in the Paris Agreement (see Table 1). Hypothetically, if for instance $70 \%$ of the LDCs and SIDS would include a certain topic in their NDCs, compared to only $40 \%$ of the emerging countries, and only $10 \%$ of the Annex I countries, such cascading would demonstrate self-differentiation through NDCs with respect to that topic. By contrast, when similar percentages of emerging countries and LDCs and SIDS include a certain topic, no cascading is demonstrated, meaning self-differentiation would continue to be dichotomous. The method is described in more detail in the online Supplementary Information.

Mitigation and adaptation. We demonstrate that the selfdifferentiation in the NDCs is consistent with the subtle differentiation of the Paris Agreement for both mitigation and adaptation.

Without judging countries' actual mitigation targets countries set in their NDCs, our analysis shows that the type of mitigation targets are cascading. All Annex I countries, except for Turkey, have absolute emission reduction targets, compared to $16 \%$ of the emerging countries and 9\% of the LDCs and SIDS (Fig. 1). In line with Article 4.4 of the Paris Agreement, which states that developed countries should take the lead by undertaking economy-wide absolute emission reduction targets, and that developing countries are 'encouraged to move over time' towards 


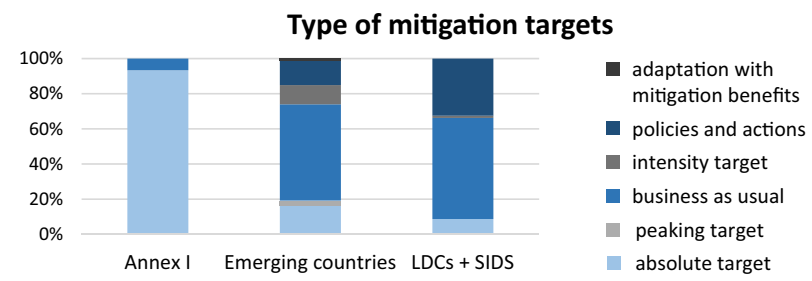

Fig. 1 Types of mitigation targets in NDCs per country category. Data based on Pauw et al. (2016)

economy-wide targets, we assume absolute emission reduction targets to be the most stringent type of target. It is important to note, however, that a stringent type of target does not automatically translate into an ambitious reduction target. For example, according to Climate Action Tracker (2019), Russia's absolute emission reduction target is 'critically insufficient', because it would not require a decrease in greenhouse gas emissions from current levels, whereas Morocco's business as usual target is ambitious in that it is compatible with limiting global warming to $1.5^{\circ} \mathrm{C}$. All else being equal, however, absolute emission reduction targets can generally be considered the most stringent type of targets The extent to which countries' emission reductions or limitations themselves cascade is not considered in our analysis, because this cannot be done without a precise understanding of the economy-wide mitigation potential and its costs in all the 195 countries that submitted NDCs.

The emerging countries take on various types of commitments, where a peaking target (3\% of emerging countries) is arguably the second-most stringent type of commitment. A majority of both the emerging countries (55\%) and the LDC + SIDS (58\%) set business-as-usual type of targets, meaning they aim to reduce their emission levels below their projected emissions under a business-as-usual scenario. Among LDCs and SIDS, the second largest type of target is 'policies and actions' (33\%). This is one of the least stringent types of commitments, even if the targets themselves can be ambitious for the respective countries (Hof et al. 2017). However, the type of target can be considered to reflect the subtle differentiation in the Paris Agreement (see Article 4.6 and Table 1), which states that LDCs and SIDS may prepare and communicate strategies, plans and actions for low GHG emission development reflecting their special circumstances. The above does not take into account to what extent the implementation of contributions is dependent on external support (see Section 3.2) as it is out of the scope of this study. Zimm and Nakicenovic (2019) and Pauw et al. (2019) analyse the implications of conditionality on feasibility and equity of NDC implementation in more detail.

The inclusion of adaptation in NDCs is cascading in this same sequence of country categories. Following the NDC Explorer (see the supplementary online material for further details), the inclusion of adaptation is defined as the explicit elaboration on actions, plans or strategies for the five most common adaptation sectors in NDCs: water, agriculture, health, biodiversity/ecosystems and forestry. This reflects whether countries consider adaptation a 'key component of and contribution to the global response to climate change' (UNFCCC, 2015; Article 7.2 and Table 1).

This article cannot indicate what ideal 'cascading' would look like for adaptation in terms of consistency with the subtle differentiation in the Paris Agreement, primarily because the Paris Agreement does not make communicating information on adaptation mandatory in NDCs. In addition, detailed baselines of countries' adaptation efforts and needs would be required. Although emerging countries have the highest percentage (14\%)

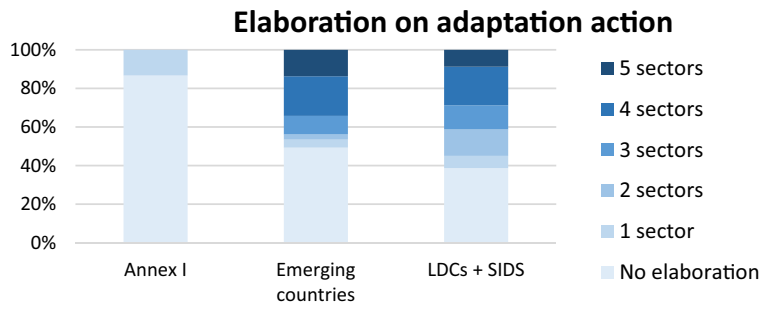

Fig. 2 Elaboration of adaptation actions/plans/strategies for adaptation in NDCs per country category. Data based on Pauw et al. (2016)

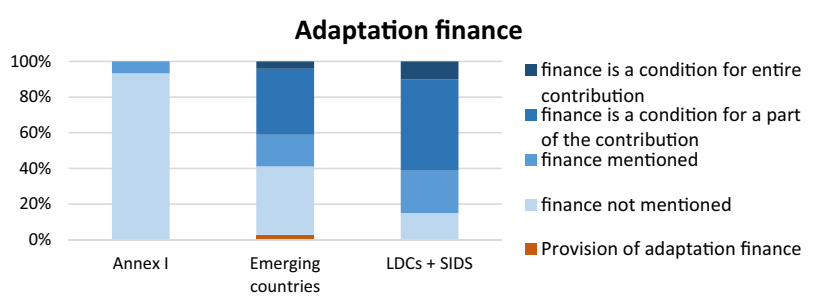

Fig. 3 Inclusion of adaptation finance in NDCs per country category. Data based on Pauw et al. (2016)

of NDCs that include actions, plans or strategies for all five sectors (see Fig. 2), LDCs and SIDS include adaptation most strongly. The validity of the findings is underlined by similar cascading with regard to NDCs' mentioning of vulnerable sectors and climate risks, or the number of countries that include adaptation cost indications in their NDCs (see Pauw et al. 2016).

Another way in which subtle differentiation with respect to adaptation is put in practice is the recognition of the importance of support for and international cooperation on adaptation efforts, in Article 7.6 of the Paris Agreement. This will be dealt with in the next section.

Climate finance, capacity building and technology transfer. Results for climate finance, technology transfer and capacity building also look as if they cascade (see Figs. 3 to 6). However, while cascading is clearly visible for requests for support, no cascade can be observed for pledges for support. As in the case of adaptation, this article cannot prescribe what 'ideal' cascading would look like with respect to consistency with the Paris Agreement's subtle differentiation. On the one hand, the Paris Agreement does not include indications that would justify such prescriptions. On the other hand, it is outside the scope of this article to provide an expectation based on the extent to which support requests and provision in NDCs reflect either existing flows of support, or the needs of countries (see e.g., Betzold and Weiler (2017) and Klöck et al. (2018) for debates on climate finance allocation). Below we describe the cascading for both requests for support and later for provision of support.

In terms of requests for support, cascading is clearly visible for both adaptation finance (See Fig. 3) and mitigation finance (see Fig. 4). Apart from Turkey, Annex I countries do not mention adaptation or mitigation finance. Self-differentiation is consistent with the subtle differentiation of Article 9.4 in the sense that $61 \%$ of the LDCs and SIDS indicate that they can only implement their adaptation contribution if this is partly or completely financed through international support, whereas only $41 \%$ of the emerging countries does so. This difference is similar for mitigation finance (80\% versus $60 \%$ ).

The other forms of subtle differentiation related to finance cannot be analysed in NDCs: communication outputs (Article 9.5 


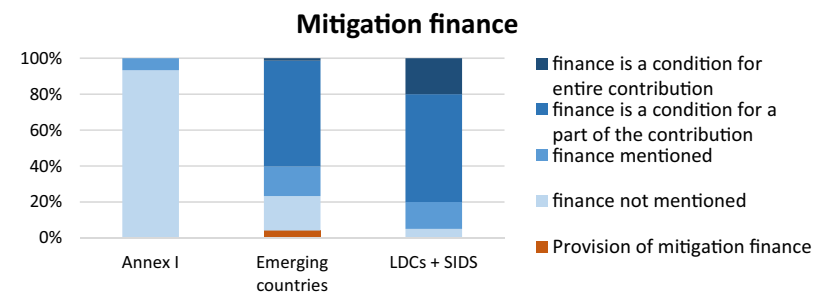

Fig. 4 Inclusion of mitigation finance in NDCs per country category. Data based on Pauw et al. (2016). Note that Chile and Panama are categorised under 'provision of mitigation finance', even though they also indicate that they want to receive mitigation finance

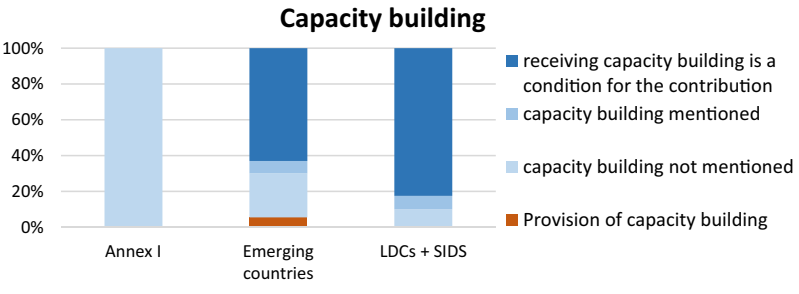

Fig. 5 Inclusion of capacity building in NDCs per country category. Data based on Pauw et al. (2016)

and 9.7) are not described in NDCs, nor are simplified approval procedures and enhanced readiness support (Article 9.9).

Similar to mitigation finance, $63 \%$ of the emerging countries and $83 \%$ of the LDCs and SIDS indicate that the implementation of their NDC depends on receiving capacity-building support (see Fig. 5). This self-differentiation is consistent with Article 11.1 (see Table 1).

Lastly, self-differentiation of support for technology transfer in NDCs is consistent with the differentiated specific needs as indicated in the Paris Agreement (UNFCCC, 2015; preamble). Overall, $63 \%$ of the emerging countries and $76 \%$ of the LDCs and SIDS make their contributions dependent on receiving technology transfer (see Fig. 6).

However, self-differentiation on provision of support in the NDCs is not consistent with the subtle differentiation of the Paris Agreement. None of the Annex I countries describe the provision of financial support in their NDCs, whereas some 'other Parties' (UNFCCC, Article 9.2) do, in this case the emerging countries of Brazil, Chile and Panama. Similarly, not a single Annex I country describes the provision of support for capacity building, but three emerging countries do. This is not consistent with Article 11.3 of the Paris Agreement, which describes that all Parties should cooperate to enhance the capacity of developing countries, and that developed countries should enhance support for capacitybuilding actions in developing countries. Finally, none of the Annex I countries state that they will provide technology transfer in their NDCs, whereas four emerging countries do.

So while potential recipient countries describe their need for support in their NDCs, potential donor countries hardly document their intentions to provide support. It thus appears that in terms of financial support, self-differentiation through NDCs is not consistent with the subtle differentiation in the Paris Agreement. The Paris Agreement carefully balanced increased mitigation action (and associated transparency requirements) by developing countries with increased support by developed countries. Indications that financial support is not forthcoming could, in line with Pauw et al. (2019), result in recipient countries refusing to make their NDCs more ambitious, as well as tensions between country groupings at the UNFCCC negotiations.

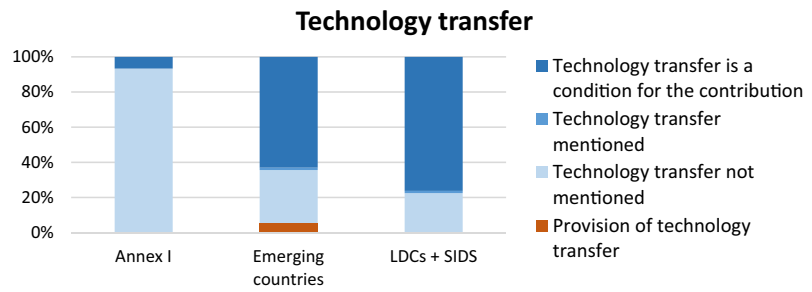

Fig. 6 Inclusion of technology transfer in NDCs per country category. Data based on Pauw et al. (2016). Note that India is categorised under 'provision of technology transfer' (next to Brazil, Chile and China), even though India also indicates it wants to receive technology transfer

\section{Discussion}

The preceding analysis demonstrates that self-differentiation in the NDCs is consistent with subtle differentiation of the Paris Agreement, except for the provision of support (finance, capacity building and technology transfer). This inconsistency raises two important questions in the context of the updating of NDCs by 2020 .

First, should future NDCs include information about the provision of financial, capacity-building and technology transfer support? It can be argued that climate finance, technology transfer and capacity building increase the global ambition to address climate change, and therefore, consequently contribute to achieving the goal of the UNFCCC (Pickering et al. 2015; Rai et al. 2015). However, developed countries have for long maintained the position that NDCs should not include information on the provision of finance (IISD, 2014, 2018), and the NDC formulation guidance adopted at the climate conference in Katowice, Poland in 2018 does not require countries to do so (UNFCCC, 2018). Indeed, it can be argued that there are other reporting formats to communicate the provision of support, including the new ex ante climate finance communication introduced in Article 9.5 of the Paris Agreement and the Biennial Transparency Reports (the first of which are due by the end of 2024) pursuant to Article 9.7 and Article 13.10. However, while the ex ante information arguably fulfils a similar function to what we suggest here, the ex post information reported under the Paris Agreement's transparency framework serves a different purpose, namely to show whether donor countries deliver on the support they have pledged. In addition, when countries indicate their planned support around the same time that developing countries are considering increasing their own ambition can offer importance reassurances to developing countries that support for them to implement their NDC will be forthcoming. Finally, including information on the provision of support for 5 years-rather than for every 2 years-arguably also strengthens the medium-term predictability of finance.

Second, is the Paris Agreement's ambition mechanism being undermined because self-differentiation on the provision of support is not consistent with the subtle differentiation in the Paris Agreement? We argue it may well be. One-hundred-andthirty-six developing countries have indicated that the implementation of their NDCs is dependent on at least one type of international support (see Pauw et al., 2019), meaning that they cannot be held to account for failing to implement their NDC if they do not receive this support. More concretely, in reporting on the implementation and achievement of their NDCs under the transparency framework of Article 13, they can point to these conditions in their NDCs.

At the same time, developed countries that provide international support can also not be held to account for the implementation-or lack thereof-of such conditional NDCs by developing countries. In other words, developing country NDCs 
could be left unimplemented and no one would be accountable. The provision of ex ante information by developed countries about their planned support through other means of communication (e.g., Article 9.5) might improve the implementation of NDCs in developing countries, but this does not clarify who can be held to account as long as such support is not earmarked for NDC implementation. A consequence of developing country failure to implement and achieve its conditional NDC may be finger pointing between developed and developing countries; a situation that could be prevented by developed countries explicitly including support for NDC implementation in their own NDCs.

These two questions need to be addressed politically. If selfdifferentiation is consistent with subtle differentiation, the Paris Agreement's CBDR-RC compromise would be operationalised, and NDCs would be able to fulfil their role as main vessels to implement the Paris Agreement. Therefore, we recommend that developed countries include in their NDCs their planned support to developing countries for NDC implementation (Pauw et al. (2018); UN-OHLLRS (2019); UNESCO (2018); UNFCCC (2019); UNFCCC (2014); UNFCCC (2013); UNFCCC (1997); United Nations (1992)).

\section{Data availability}

The datasets generated during and/or analysed during the current study are available in through the NDC Explorer (10.23661/ ndc_explorer_2017_2.0). See: www.NDCexplorer.info.

Received: 26 March 2019 Accepted: 15 July 2019

Published online: 30 July 2019

\section{References}

BASIC Experts (2011) Equitable access to sustainable development: Contribution to the body of scientific knowledge. BASIC expert group: Beijing, Brasilia, Cape Town and Mumbai

Betzold C, Weiler F (2017) Allocation of aid for adaptation to climate change: do vulnerable countries receive more support? Int Environ Agreem: Polit, Law Econ 17:17-36

Bodansky D (2016) The Paris climate change agreement: A new hope? Am J Int Law 110:288-319. https://doi.org/10.5305/amerjintelaw.110.2.0288

Brown DA, Breakey H, Burdon P, Mackey B, Taylor P (2018) A four-step process for formulating and evaluating legal commitments under the Paris Agreement. Carbon Clim Law Rev 12:98-109

Ciplet D, Roberts JT, Khan M (2013) The politics of international climate adaptation funding: Justice and divisions in the greenhouse. Glob Environ Polit 13:49-68

Climate Action Network (2013) Equity reference frameworks at the UNFCCC process. CAN

Climate Action Tracker (2019) Climate action tracker. https://climateactiontracker. org/countries/. Accessed 7 July 2019

Deleuil T (2012) The common but differentiated responsibilities principle: Changes in continuity after the Durban conference of the parties. Rev Eur Community Int Environ Law 21:271-281

Depledge J and Yamin F (2009) The global climate-change regime: a defence. In: Helm D, Hepburn C (eds.) The economics and politics of climate change. Oxford University Press, Oxford, p 433-453

Du Pont YR, Jeffery ML, Gütschow J, Rogelj J, Christoff P, Meinshausen M (2017) Equitable mitigation to achieve the Paris Agreement goals. Nat Clim Change $7(1): 38$

Dubash NK (2009) Copenhagen: climate of mistrust. Econ Polit Wkly 44:8-11

Grieco J, Powell R, Snidal D (1993) The relative-gains problem for international cooperation. Am Political Sci Rev 87:727-743

Hermwille L, Obergassel W, Ott HE, Beuermann C (2017) UNFCCC before and after Paris-what's necessary for an effective climate regime? Clim Policy 17:150-170

Hof AF, den Elzen MGJ, Admiraal A et al. (2017) Global and regional abatement costs of Nationally Determined Contributions (NDCs) and of enhanced action to levels well below $2{ }^{\circ} \mathrm{C}$ and $1.5^{\circ} \mathrm{C}$. Environ Sci Policy 71:30-40. https://doi.org/10.1016/j.envsci.2017.02.008

IISD (2014). Summary of the Lima climate change conference: 1-14 December. Earth Negotiations Bulletin. Vol 12 (169). New York, USA

IISD (2018). Summary of the Katowice Climate Change Conference: 2-15 December. Earth Negotiations Bulletin, Vol 12 (747). New York, USA
IPCC (2013) Climate Change 2013: The physical science basis. Contribution of working group I to the fifth assessment report of the intergovernmental panel on climate change. Cambridge University Press, Cambridge, UK and New York, USA

Kartha S, Athanasiou T, Caney S, Cripps E, Dooley K, Dubash N, Fei T, Harris P, Holz C, Lahn B, Moellendorf D, Müller B, Roberts T, Sagar A, Shue H, Singer P, Winkler H (2018) Cascading biases against poorer countries. Nat Clim Change 8:348-349

Klinsky S, Winkler H (2014) Equity, sustainable development and climate policy. Clim Policy 14:1-7

Klöck C, Molenaers N, Weiler F (2018) Responsibility, capacity, greenness or vulnerability? What explains the levels of climate aid provided by bilateral donors? Environ Polit 27:892-916

Makomere R, Mbeva K (2018) Squaring the circle: Development prospects within the Paris Agreement. Carbon Clim Law Rev 12:31-40

Mbeva K, Pauw WP (2016) Self-differentiation of countries' responsibilities: addressing climate change through Intended Nationally Determined Contributions, Discussion Paper 4/2016. German Development Institute/Deutsches Institut für Entwicklungspolitik (DIE), Bonn, Germany

Mearsheimer J (1994) The false promise of international institutions. Int Secur 1:5-49

Pauw WP, Bauer S, Richerzhagen C et al. (2014) Different Perspectives on Differentiated Responsibilities. A State-of-the-Art Review of the Notion of Common but Differentiated Responsibilities in International Negotiations, Discussion Paper 6/2014. German Development Institute/Deutsches Institut für Entwicklungspolitik (DIE), Bonn, Germany

Pauw WP, Castro P, Pickering J, Bhasin S (2019) Conditional nationally determined contributions in the Paris Agreement: foothold for equity or achilles heel? Clim Policy. https://doi.org/10.1080/14693062.2019.1635874

Pauw WP, Klein RJT, Mbeva K, Dzebo A, Cassanmagnago D, Rudloff A (2018) Beyond headline mitigation numbers: we need more transparent and comparable NDCs to achieve the Paris Agreement on climate change. Clim Change 147:123-129

Pauw WP, Cassanmagnago D, Mbeva K et al. (2016) NDC Explorer. German Development Institute/Deutsches Institut für Entwicklungspolitik (DIE), and African Centre for Technology Studies (ACTS), Bonn, Germany and Nairobi, Kenya. https://klimalog.die-gdi.de/ndc/

Pickering J, Jotzo F, Wood PJ (2015) Sharing the Global Climate Finance Effort Fairly with Limited Coordination. Glob Environ Polit 15:39-62

Rai N, Soanes M, Norton A, Anderson S, Steele P, Tenzing J and MacGregor J (2015) A fair climate deal in Paris means adequate finance to deliver INDCs in LDCs, IIED Briefing. IIED, London

Rajamani L (2015) Negotiating the 2015 climate agreement: issues relating to legal form and nature. Research Paper 28. Mitigation Action Plans \& Scenarios, Cape Town, South Africa, p 26

Rajamani L (2016) Ambition and differentiation in the 2015 Paris Agreement: Interpretative possibilities and underlying politics. Int Comp Law Q 65:493-514

UN-OHLLRS (2019) Criteria for Identification and Graduation of LDCs. United Nations Office of the High Representative for the Least Developed Countries, Landlocked Developing Countries and Small Island Developing States. http:// unohrlls.org/about-ldcs/criteria-for-ldcs/. Accessed 7 July 2019

UNESCO (2018) UNESCO list of small islands developing states (SIDS). http://www. unesco.org/new/en/natural-sciences/priorityareas/sids/resources/sids-list/

UNFCCC (2018) Katowice Climate Package. UNFCCC, Bonn

UNFCCC (2019) Party groupings. https://unfccc.int/process-and-meetings/partiesnon-party-stakeholders/parties/party-groupings. Accessed 7 July 2019

UNFCCC (2015) Adoption of the Paris Agreement. UNFCCC, Bonn

UNFCCC (2014) Report of the Conference of the Parties on its twentieth session. UNFCCC, Bonn

UNFCCC (2013) Report of the Conference of the Parties on its nineteenth session. UNFCCC, Bonn

UNFCCC (2010) Report of the Conference of the Parties on its fifteenth session, held in Copenhagen from 7 to 19 December 2009. UNFCCC, Bonn

UNFCCC (1997) Kyoto Protocol to the United Nations Framework Convention on Climate Change. UNFCCC, Bonn

United Nations (1992) United Nations Framework Convention on Climate Change. https://unfccc.int/resource/docs/convkp/conveng.pdf

Voigt C, Ferreira F (2016) 'Dynamic Differentiation': The principles of CBDR-RC, progression and highest possible ambition in the Paris Agreement. Transnatl Environ Law 5:285-303

Winkler H, Höhne N, Cunliffe G et al. (2018) Countries start to explain how their climate contributions are fair: more rigour needed. Int Environ Agreem Polit Law Econ 18:99-115. https://doi.org/10.1007/s10784-017-9381-x

Zimm C, Nakicenovic N (2019) What are the implications of the Paris Agreement for inequality? Clim Policy. https://doi.org/10.1080/14693062.2019.1581048

\section{Acknowledgements}

We also thank the audience at the 2018 Earth System Governance Conference, where an earlier version of this article was presented. Finally, we thank the Frankfurt School of 
Finance and Management, the University of Eastern Finland and the African Centre for Technology Studies for their financial contribution to make this article available open access. KM further acknolwedges funding from the German Federal Ministry of Education and Research (BMBF), through the Green Talents Fellowship, for a research stay at the German Development Institute/Deutsches Institut für Entwicklungspolitik (DIE) during the early stages of this research.

\section{Additional information}

The online version of this article (https://doi.org/10.1057/s41599-019-0298-6) contains supplementary material, which is available to authorised users.

Competing interests: The authors declare no competing interests.

Reprints and permission information is available online at http://www.nature.com/ reprints

Publisher's note: Springer Nature remains neutral with regard to jurisdictional claims in published maps and institutional affiliations. (c) (i) Open Access This article is licensed under a Creative Commons Attribution 4.0 International License, which permits use, sharing, adaptation, distribution and reproduction in any medium or format, as long as you give appropriate credit to the original author(s) and the source, provide a link to the Creative Commons license, and indicate if changes were made. The images or other third party material in this article are included in the article's Creative Commons license, unless indicated otherwise in a credit line to the material. If material is not included in the article's Creative Commons license and your intended use is not permitted by statutory regulation or exceeds the permitted use, you will need to obtain permission directly from the copyright holder. To view a copy of this license, visit http://creativecommons.org/ licenses/by/4.0/.

(C) The Author(s) 2019 